\title{
MENANGKAL DEGRADASI MORAL DI ERA DIGITAL BAGI KALANGAN MILLENIAL
}

\author{
${ }^{1}$ Ahmad Yani Nasution, ${ }^{2}$ Moh Jazuli \\ Dosen Fakultas Ekonomi Universitas Pamulang \\ Email : $\underline{1 \text { dosen01583@unpam.ac.id }}$
}

\begin{abstract}
ABSTRAK
Kalangan millenial . Masa depan suatu bangsa sesungguhnya dipegang oleh para pemuda yang merupakan masyarakat yang berada pada usia remaja, maka dari itu penting sekali bangsa ini untuk meningkatkan kualitas para pemudanya untuk Indonesia yang lebih baik. Para Dosen agama Universitas Pamulang melihat fenomena yang berkembang di masyarakat tentang semakin menjauhnya Agama terhadap kehidupan bermasyarakat yang diakibatkan perkembangan teknologi digital yang semakin merebak di era digital akhirnya berdampak pada perkembangan pembelajaran PAI di lingkungan MTs Insan Madani Kp. Rahong Desa Tegallega Kecamatan Cigudeg Kabupaten Bogor, dengan mengkaji masalah tersebut maka diperlukan tindakan nyata minimal mengadakan sosialisasi dan implementasi tentang pentingnya pemanfaatan teknologi sehingga dapat dijadikan solusi yang tepat.

Kegiatan Pengabdian Kepada Masyarakat dengan tema "Menangkal Degradasi Moral di Era Digital bagi kalangan Millenial dilaksanakan oleh tim pengabdian kepada masyarakat program studi Manajemen Universitas Pamulang yang terdiri dari para dosen agama Universitas Pamulang untuk menjawab fenomena di atas.

Kegiatan berlangsung selama tiga hari. Acara ini terlaksana atas kerjasama dengan berbagai pihak seperti Yayasan Sasmita Jaya, dosen Program Studi Manajemen serta pengurus di Mts Insan Madani. Pelatihan ini berhasil memberikan bekal softskill kepada anak-anak remaja di Mts tersebut.

Saran dari pelatihan menangkal degradasi moral dalam rangka kegiatan pengabdian kepada masyarakat ini adalah hendaknya tim dosen ataupun berbagai pihak lainnya turut serta dalam mendukung program untuk membuat para generasi muda, termasuk pemuda agar mempunyai bekal moral yang baik yang berguna bagi mereka. Tidak hanya itu anak-anak remaja harus diarahkan dan dibantu agar tidak hanya cerdas dalam akademis tapi juga mempunyai kemampuan softskill yang baik, terutama baik anak-anak remaja yang sedang mencari jati diri. Harapannya pelatihan-pelatihan semacam ini dapat terus dilaksanakan dan ditingkatkan pada setiap jenjang pendidikan.
\end{abstract}

Kata Kunci : Degradasi Moral, Era Digital Dan Millenial 


\section{PENDAHULUAN}

Sebuah perguruan tinggi berkewajiban melaksanakan Tri Darma Perguruan Tinggi berupa pendidikan, penelitian, dan pengabdian kepada masyarakat $(\mathrm{P} 3 \mathrm{KM})$. Diharapkan dengan P3KM tersebut keberadaan perguruan tinggi dapat memberikan kontribusi besar kepada pengembangan keilmuan dan pengabdian kepada masyarakat. Universitas Pamulang (Unpam) adalah salah satu Perguruan Tinggi Swasta yang secara konsisten menyelenggarakan P3KM. Pelaksanaan P3KM di Universitas Pamulang di bawah kendali Lembaga Penelitian dan Pengabdian Kepada Masyarakat (LP2M).

LP2M Universitas Pamulang memegang peranan yang sangat penting dalam mendorong dan mengarahkan kegiatan-kegiatan penelitian dan pengabdian kepada masyarakat sebagai wujud Tri Dharma Perguruan Tinggi. Setiap kegiatan P3KM yang diselenggarkan oleh seluruh Program Studi (Prodi) di Unpam harus berkoordinasi dengan LP2M. Khususnya saat ini LP2M sedang gencar mengkampanyekan Pengabdian Kepada Masyarakat (PKM). Program PKM yang akan dilaksanakan, disesuaikan dengan bidang keilmuan di setiap Prodi dan kebutuhan masyarakat.

Para Dosen Agama Islam Universitas Pamulang melihat adanya fenomena degradasi moral di era digital pada kalangan milenial. Degradasi berarti kemunduran, kemerosotan atau penurunan dari suatu hal. Sedangkan moral adalah akhlak atau budi pekerti menurut Kamus Besar Bahasa Indonesia. Jika kita interpretasikan keduanya maka degradasi moral merupakan suatu fenomena adanya kemerosotan atas budi pekerti seseorang maupun sekelompok orang sesuai dalam konteks Bangsa Indonesia. Adapun kalangan millennial saat ini akrab terdengar dan dapat diartikan secara sederhana sebagai orang-orang yang memiliki interaksi kuat terhadap sosial media melalui gawai seperti PC, HP, tablet, dan benda-benda digital. Artinya kalangan millennial memiliki akses yang bebas dengan globalisasi dunia, yang tentunya pasti akan mempengaruhi moral.

Banyak diantara kalangan millennial yang telah menunjukkan degradasi moral seperti minimnya sopan santun (cara berbicara dan berpakaian), kenakalan remaja (sex bebas dan konsumsi obat-obat terlarang), jauh dari nilai-nilai agama. Adanya fenomena tersebut melatarbelakangi para dosen agama islam Universitas Pamulang untuk memberikan materi pelatihan melalui persentasi dan diskusi dikalangan siswa-siswi Mts Insan Madani. Bagaimanapun juga siswa-siswi adalah anak- atau generasi penerus bangsa yang akan menghadapi tantangan dari fenomena tersebut.

"Problem Pengembangan Moral Remaja dalam Perspektif Pendidikan Islam" . Kemerosotan Moral di Kalangan Remaja: Sebuah penelitian mengenai Parenting Styles dan Pengajaran Adab .

Tujuan dari PKM ini adalah memberikan pemahaman terkait degradasi moral di kalangan millennial, memberikan pemahaman terkait upaya dalam menangkal degradasi moral di era digital. Manfaat dari kegiatan PKM ini adalah peserta didik mendapatkan materi dan termotivasi untuk menangkal terjadinya degradasi moral yang menjadi tantangan di kalangan millennial di era digital. 
Solusi yang dipilih untuk menangani adanya fenomena degradasi moral di era digital pada kalangan millennial ialah dengan memberikan wawasan keagamaan, meningkatkan keimanan dan ibadah, memberikan pemahaman bagaimana cara bermedia sosial yang baik

\section{METODE PELAKSANAAN KEGIATAN}

PKM dilaksanakan di Mts Insan Madani Kp. Rahong Desa Tegallega Kecamatan Cigudeg Kabupaten Bogor pada hari Senin sampai dengan Rabu, tanggal 17 sampai 19 Desember 2019. Adapun Waktu pelaksanaannya dari pukul 13.30 sampai dengan 17.00 WIB. Subjek dari kegiatan PKM adalah siswa - Siswi Mts Insan Madani tersebut. Metode yang digunakan adalah pelatihan dengan cara memberikan presentasi dan diskusi antara pemateri dan peseerta.

\section{HASIL DAN PEMBAHASAN}

Kegiatan PKM yang dilaksanakan memiliki beberapa tahapan yang dilakukan sebelu berkunjung langsung. Yang pertama dilakukan ialah tahap persiapan, yakni dengan melakukan survei awal. Pada tahap ini, dilakukan wawancara dengan kepala sekolah Mts Insan Madani terkait prosedur kegiatan PKM. Diantaranya pemantapan lokasi dan peserta PKM, penyusunan bahan pelatihan PKM.

Adapun pemateri pada pelatihan ini adalah Ahmad Yani Nasution berisikan "Fenomena Degradasi Moral di Era Digital pada kalangan millennial", dengan moderator Firdaus. Selanjutnya dilanjutkan oleh Muhammad Jazuli dengan judul materi "Solusi Menghadapi Degradasi Moral ", yang dimoderatori oleh Ahmad Yani Nasution.

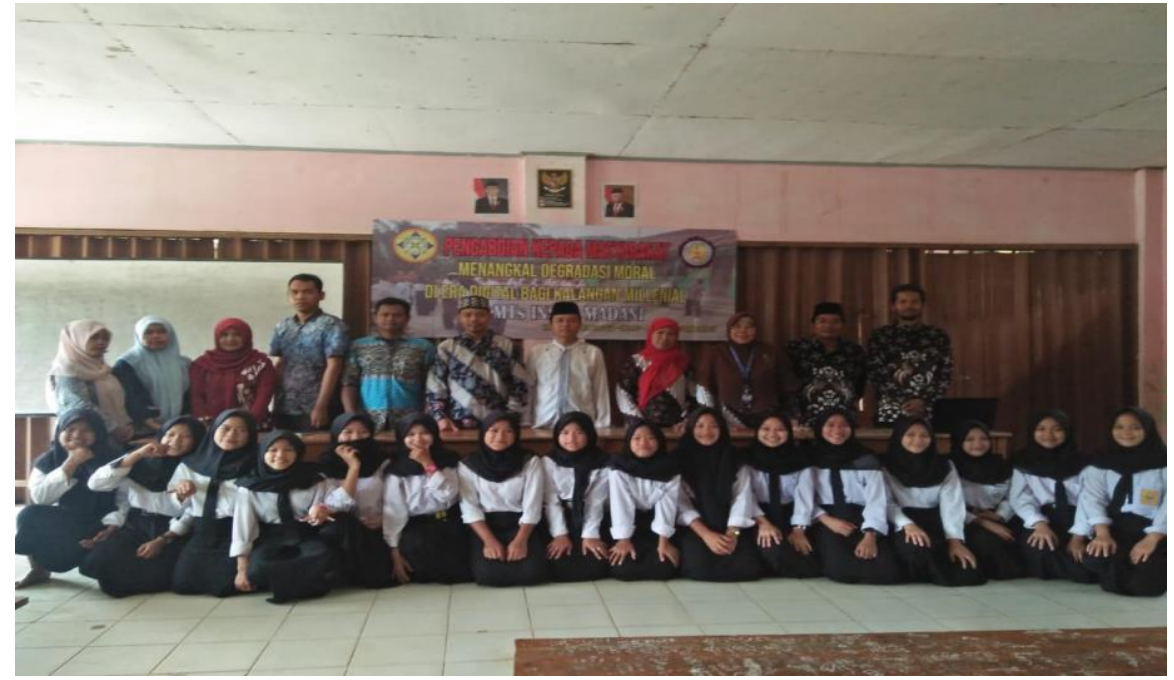

Gambar 1. Foto Bersama Peserta PKM

Di dalam sesi pelatihan atau sesi inti ini terlihat peserta sangat antusias sekali di mana terbukti banyak pertanyaan yang diajukan oleh peserta, diantaranya pertanyaan "Apakah globalisasi berpengaruh terhadap degradasi moral suatu 
bangsa? Pertanyaan ini dijawab oleh Ahmad Yani Nasution sebagai berikut: "Globalisasi memudahkan kita mengakses segala sesuatu dari mana saja, termasuk dari kiblat Barat yang tentu saja memiliki standar moral yang berbeda dengan Indonesia; sehingga saat kalangan millennial meniru gaya hidup tersebut dianggap telah melakukan degradasi moral; moral yang baik adalah yang telah dicontohkan oleh Rasulullah SAW dengan standar Al-Qur'an dan hadits.

Kemudian pada pertanyaan kedua "Bagaimana metode dakwah yang tepat bagi kalangan milenial?" Kemudian Muhammad Jazuli (Pemateri kedua) Menjawab bahwa dakwah yang efektif di kalangan millennial adalah dengan memberikan wawasan keagamaan, meningkatkan keimanan dan ibadah, memberikan pemahaman bagaimana cara bermedia sosial yang baik.

Siswa sangat antusias mengkuti kegoatan PKM yang dilakukan oleh TIM PKM dari Universitas Pamulang karena kegiatan PKM dilakukan dalam bentuk pengarahan yang disertai games dan kegiatan seru lainnya

\section{KESIMPULAN DAN SARAN}

Kegiatan PKM dengan tema "Menangkal Degradasi Moral di Era Digital bagi kalangan Millenial di Mts Insan Madani Kp. Rahong Desa Tegallega Kecamatan Cigudeg Kabupaten Bogo Bogor yang telah dilaksanakan oleh tim pengabdian kepada masyarakat program studi Manajemen Universitas Pamulang terlaksana dengan baik sesuai dengan yang direncanakan

Saran dari pelatihan menangkal degradasi moral dalam rangka kegiatan PKM ini adalah hendaknya tim dosen ataupun berbagai pihak lainnya turut serta dalam mendukung program untuk membuat para generasi muda, termasuk pemuda agar mempunyai bekal moral yang baik yang berguna bagi mereka. Tidak hanya itu Siswa harus diarahkan dan dibantu agar tidak hanya cerdas dalam akdemis tapi juga mempunayi kemampuan softskill yang baik, terutama bagi siswa yang sedang mencari jati diri. Harapannya pelatihan-pelatihan semacam ini dapat terus dilaksanakan dan ditingkatkan.

Kegiatan pengabdian kepada masyarakat adalah salah satu kewajiban dosen untuk memenuhi kewajiban Tri Dharma Perguruan Tinggi yang menjadi aksi dari keterlibatan perguruan tinggi dalam pembangunan nasional. Dari kegiatan ini, masyarakat juga akan mendapatkan bekal untuk menyelesaikan permasalahan dan menjawab tantangan dalam kehidupannya. Masyarakat juga nantinya akan memberikan pembelajaran bagi perguruan tinggi tentang realitas kehidupan.

Diharapkan PKM yang dilaksanakan dengan sasaran Siswa di Mts Insan Madani Kp. Rahong Desa Tegallega Kecamatan Cigudeg Kabupaten Bogo Bogor ini dapat bermanfaat kepada semua pihak yang terlibat baik secara langsung ataupun tidak. Selain itu diharapkan PKM ini dapat menginspirasi berbagai pihak untuk terus mendukung berbagai kegiatan yang serupa 


\section{DAFTAR PUSTAKA}

A Sobarna, S Hambali, S Sutiswo, D Sunarsi. (2020). The influence learning used $\mathrm{ABC}$ run exercise on the sprint capabilities. Jurnal Konseling dan Pendidikan 8 (2), 67-71

A Sudarsono, D Sunarsi. (2020). Pengaruh Kualitas Pelayanan Dan Varian Produk Terhadap Keputusan Pembelian Pada Laboratorium Klinik Kimia FarmaBintaro. Value: Jurnal Manajemen dan Akuntansi 15 (1), 16-26

Azra, Azyumardi.Pendidikan Islam di Era Globalisasi: Peluang dan Tantangan, [EDUKASI: Jurnal Penelitian Pendidikan Agama dan Keagamaan 2017] 6.4 .

D Prasada, S Sarwani, M Catio. (2019). Pengaruh Kompensasi Dan Lingkungan Kerja Terhadap Kinerja Karyawan Pada PT. Mitra Adiperkasa, Tbk. Jurnal Manajemen, Bisnis dan Organisasi (JUMBO) 3 (3), 195-207

D Sunarsi. (2014). Pengaruh Gaya Kepemimpinan, Motivasi dan Disiplin Kerja Terhadap Kinerja Pendidik. Universitas Pamulang

Diah Ningrum, UNISIA, Vol. XXXVII No. 82 Januari 2015. Edukasia Islamika : Volume 1, Nomor 1, Desember 2016/1438

Gumilar, I., Sunarsi, D. (2020). Comparison of financial performance in banking with high car and low car (Study of banks approved in the kompas 100 index for the period 2013-2017). International Journal of Psychosocial Rehabilitation. Volume 24 - Issue 7

Jasmani, J., \& Sunarsi, D. (2020). The Influence of Product Mix, Promotion Mix and Brand Image on Consumer Purchasing Decisions of Sari Roti Products in South Tangerang. PINISI Discretion Review, 1(1), 165-174.

L Nofiana, D Sunarsi. (2020). The Influence of Inventory Round Ratio and Activities Round Ratio of Profitability (ROI). JASa (Jurnal Akuntansi, Audit dan Sistem Informasi Akuntansi) 4 (1), 95-103

L Nofiana, D Sunarsi. (2020). The Influence of Inventory Round Ratio and Activities Round Ratio of Profitability (ROI). JASa (Jurnal Akuntansi, Audit dan Sistem Informasi Akuntansi) 4 (1), 95-103

Maddinsyah, A., Sunarsi, D., Hermawati, R., Pranoto. (2020). Analysis of location selection effect on the user decision that influcence the success of the service business of micro, small and medium enterprise (MSME) in bandung timur region. International Journal of Advanced Science and Technology. Vol. 29 No. 06

Nursyifa, A. (2018). Kajian Cultural Lag dalam Kehidupan Masyarakat Perkampungan Budaya Betawi Setu Babakan Pada Era Globalisasi. Jurnal Pendidikan Kewarganegaraan, 5(1), 1-24. Retrieved fromhttp://openjournal.unpam.ac.id/inde

Purwanti, P., Sarwani, S., \& Sunarsi, D. (2020). Pengaruh Inovasi Produk Dan Brand Awareness Terhadap Keputusan Pembelian Konsumen Pada Pt. Unilever Indonesia. Inovasi, 7(1), 24-31.

RW Amelia, D Sunarsi. (2020). Pengaruh Return On Asset Dan Return On Equity Terhadap Debt To Equity Ratio Pada Pt. Kalbe Farma, Tbk. Ad Deenar: 
Jurnal Ekonomi dan Bisnis Islam 4 (01), 105-114D Sunarsi. (2014). Pengaruh Gaya Kepemimpinan, Motivasi dan Disiplin Kerja Terhadap

Kinerja Pendidik. Universitas Pamulang

Siti Hidjatul Hidajah tahun 2012 Dinamika Ilmu Vol. 12 No. 1

Sunarsi, D. (2018). Analisis Motivasi Kerja Tenaga Pendidik Sukarela Pada Pusat

Kegiatan Belajar Masyarakat (PKBM) Bimasda Kota Tangerang Selatan.

Kreatif: Jurnal Ilmiah Prodi Manajemen Universitas Pamulang, 6(2), 53-65.

Sunarsi, D. (2019). Seminar Sumber Daya Manusia. Tangerang Selatan: Unpam Press

Sunarsi, D. (2020). Panduan Meningkatkan Kinerja Dan Kepuasan Guru. Kota Serang: Desanta Muliavisitama

Sunarsi, D., \& Asmalah, L. (2018). Pelatihan Manajemen Pengembangan Diri Bagi

Penerima Beasiswa RZIS UGM Dan Dompet Shalahuddin Jogjakarta.

Jurnal Pengabdian Dharma Laksana, 1(1), 51-60.

Sunarsi, D., \& Erlangga, A. (2020). The Effect of Leadership Style and Work

Environment on the Performance of Stationary Pump Operators in the Water

Resources Office of West Jakarta City Administration. International Journal of Advances in Social and Economics, 2(3).

Sunarsi, D., Kustini, E., Lutfi, A. M., Fauzi, R. D., \& Noryani, N. (2019).

Penyuluhan Wirausaha Home Industry Untuk Meningkatkan Ekonomi

Keluarga Dengan Daur Ulang Barang Bekas. BAKTIMAS: Jurnal

Pengabdian pada Masyarakat, 1(4), 188-193.

Sunarto, K. (2004). Pengantar Sosiologi. Jakarta: Lembaga Penerbit Fakultas Ekomoni UI.

Sunarsi, D., Kusjono, G., \& Nuryana, I. (2019). Pelatihan Manajemen Penguasaan

Kelas Dan Pembuatan Bahan Ajar Bagi Tenaga Pengajar Sukarela Taman

Belajar Kreatif Mekarsari. Jurnal Pengabdian Dharma Laksana, 2(1), 41-44.

Undang - Undang Republik Indonesia Nomor 12 Tahun 2012 Tentang Pendidikan

Tinggi Pasal 4 Ayat 9 Tentang Tridharma Perguruan Tinggi

Yuangga, K. D., \& Sunarsi, D. (2018). The Influence of Procrastination and Low

Time Management on Student Self Efficacy (at MA Soebono Mantofani).

PINISI Discretion Review, 2(1), 85-92.

Yuangga, K. D., Jasmani, J., \& Sunarsi, D. (2017). The Influence of Technology

Determinism and Technology Literacy on Student Learning Outcomes (On MA Daarul Hikmah Pamulang). PINISI Discretion Review, 1(1), 23-30. 